\title{
Optimal Bonus-Malus System Design in Motor Third-Party Liability Insurance in Turkey: Negative Binomial Model
}

\author{
Serpil Ergün Bülbül ${ }^{1} \&$ Kemal B. Baykal ${ }^{1}$ \\ ${ }^{1}$ Department of Actuary, School of Banking and Insurance, Marmara University, Istanbul, Turkey \\ Correspondence: Kemal B. Baykal, Department of Actuary, School of Banking and Insurance, Marmara \\ University, Istanbul, Turkey. Tel: 900-216-414-9989. E-mail: burak.baykal@ marmara.edu.tr
}

Received: June 24, 2016

doi:10.5539/ijef.v8n8p205
Accepted: July 16, 2016

Online Published: July 25, 2016

\begin{abstract}
One of the most significant instruments used in motor third-party liability insurance rating is bonus-malus system. The aim of the bonus-malus system is to provide a fairness of the premiums paid by ensuring that everyone pays a premium that corresponds exactly to their own claim frequency. A balance of total amount of bonuses and maluses is very important to maintain the financial stability of the insurance companies. In Turkey, free tariff regime in motor third-party liability insurance has been adopted since 2014. In this study, an experience rating was employed via the insured's individual claim experience by considering the drawbacks of using mandatory bonus-malus system. Data entailing information about the claim frequencies of automobiles over a year for motor third party liability policies were obtained from an insurance company. Optimal bonus-malus rates are determined by negative binomial model by using credibility theory, Bayesian approach and the principle of expected value premium.
\end{abstract}

Keywords: experince rating, negative binom distribution, bonus-malus, credibility, motor third party liability insurance

\section{Introduction}

Motor insurance is a liability insurance which covers the damage to third party caused by the insured. Generally, there are three types of motor insurance regimes used in the world, namely fully mandatory, semi-mandatory and free tariff regime.

In Turkey, fully mandatory has been used since 1953, and free tariff regime has been adopted since the beginning of 2014 so that the companies had the opportunity to define the bonus-malus rates on their own as well as going on using the existing class system and transition rules. Bonus-malus system used interchangeably with "no-fault discount", "merit rating", "experience rating" in different countries is based on penalizing the insureds who are responsible for one or more claims for by a premium surcharge or awarding discount of the premium (Durak \& Erdoğan, 2010; Frangos \& Vrontos, 2001).

The insureds will be awarded with one class and will take bonuses the following year if they do not make any claims. Otherwise, if the insureds make claims, they will be penalized for each claim according to transition rules. Currently, bonus-malus systems used frequently in Asian and European countries first emerged in Europe in early 1960s and it has been frequently used since then (Lemaire, 1998).

Insurers use bonus-malus systems for two main purposes: (1) to encourage drivers to drive more carefully after a year without any claim (2) to ensure that the insureds pay a premium proportional to the risk that they impose to the pool, which depends on their claim history. BMS reduces the heterogenity of risk classes using the individual claim experience (Dionne \& Ghali, 2005).

Bonus-malus system is composed of three main components, namely premium scale, initial class and transition rules (the rules that determine the transfer from one class to another when the number of claims is known). The system works as follows: an insured enters the system in the initial class, and then throughout the whole driving lifetime, the transition rules are applied upon each policy renewal to define the new class by using the claim history (Frees, 2010; Lemaire, 1998).

In Bonus-Malus systems, usually only the number of claims at fault is usually used because unobserved and unmeasurable driver characteristics affect claim frequency more than claim severity (Kaas, Goovaerts, Dhaene, 
\& Denuit, 2008).

This study aims to construct a new bonus-malus model, which is financially balanced and scientifically reliable after adopting free tariff regime. Unlike the previous bonus-malus systems in Turkey, claims distribution has been identified by using the data obtained from an insurance company and posterior claim frequencies has been found out based on credibility theory and Bayesian approach by using claims history, and the premiums has been constructed by expected value premium calculation principle.

\section{Literature Review}

Whereas studies on bonus-malus systems started during 1960s in the world, studies on this topic started in 2000s in Turkey.

Bichsel (1964) offer an expected value premium principle by suggesting that each policyholder should pay a premium propotional based on their claims and Bülhmann (1967) offers a system in which each insured pays premuim based on their own risk.

Corlier, Lemaire, and Muhokolo (1979) reveal that the constant decrease of premiums due to bonuses (discount) caused Belgian bonus-malus system to be unstable. By modelling claim frequencies via using Negative Binom (Poisson-Gamma) distribution, they created a simulation for 70 year in order to investigate mean premiums and the bonus-malus classes in which drivers are expected to be.

Dionne and Vanasse (1989) indicate how to modify a bonus-malus system which has been developed by adding regressiom component to Possion and Negative Binom by using both prior and posterior information.

Tremblay (1992) have built a bonus malus system which minimizes the insurer's risk via Possion-Inverse Gaussian distribution and quadratic loss function. The data set of Possion-Inverse Gauss model has also been employed in another study, which models a bonus-malus system based on Negative Binom distribution. The two distributions produced similar premium scales (Leamire, 1985).

Walhin and Paris (1999) have constructed two seperate bonus-malus systems by choosing parametric Hofmann distribution and non-parametric mixed Poisson distribution as a structure function and compared the results. The model created by use of mixed Poisson distribution represents the data set better than Hofmann distribution. Yet, the premiums produced by mixed Poisson model have showed volatility over the years, which cannot be put into practice. Thus, while constructing the bonus-malus scales, it can be concluded that parametric distribution (Hoffman distribution) should be preferred.

Frangos and Vrontos (2001) have built a bonus-malus system by combining Pareto distribution for claim severity and Negative Binom distribution for posterior claim frequency. Afterwards, they have offered a generalized optimal bonus-malus system which is based on the model by Dionne and Vanasse (1989). The model by Frangos ve Vrontos (2001) has combined both claim frequency and claim severity.

Morillo and Bermúdez (2003) has constructed a bonus-mlus system which uses exponential loss fuction instead of quadratic loss function. They has discovered a decrease not only in bonuses but also maluses by implementing exponential loss function.

Mert and Saykan (2005) compare a traditional bonus-malus system whose premiums based on only claim frequencies with another system whose premiums based on both claim frequencies and claim severities. They put forward that the system which can be fairer if bonus-malus rates are defined according to both claim severity through Pareto distribution and claim frequency through Geometric (Poisson-Exponential) distribution.

Durak and Erdoğan (2010), suggest another system by use of Negative Binom (Poisson-Gamma) credibility model during the application process of bonus-malus system. They have handled credibility premiums and prior rating separately. After constructing and comparing two separate premium tables, one of which including quadratic loss function and the other one entailing exponential loss function, they have identified exponential loss function produce less bonuses and maluses.

\section{Design of an Optimal Bonus-Malus System: Negative Binomial Model}

\subsection{Data}

Data obtained from an insurance company which operates in Turkey include 51093 motor third party liability insurance policy's claim frequency information for one year. The policies which have been cancelled during policy period have been excluded in this study for determining the claim frequency throughout one year. Beside this, green card policies have been left off from this study. Only policies which are valid from 01.01.2013 31.12.2013 have been included in this study. 
Table 1 summerizes 51093 obeservations of claim frequencies of motor third party liability insurances of automobiles as follows

Table 1. Observed claim frequencies

\begin{tabular}{cc}
\hline $\begin{array}{c}\text { Number of Claims } \\
(k)\end{array}$ & $\begin{array}{c}\text { Observed Frequencies } \\
\left(n_{k}\right)\end{array}$ \\
\hline 0 & 47837 \\
1 & 2908 \\
2 & 262 \\
3 & 28 \\
4 & 4 \\
$>4$ & 0 \\
Total & 51039 \\
\hline
\end{tabular}

In Table 1, the numbers of claims are indicated as $k$ and claim frequencies as $n_{k}$. As the table shows, the number of policies which has not made any claims for one year are 47.837, the number of policies which have made claims twice is 2.908 , the number of policies which have made claims third times is 28 , the number of policies which have made claims four times is 4 and non-of the policies has made any claims more then four times. Portfolio has a mean $\bar{x}=0.0692$ a variance $s^{2}=0.0789$.

\subsection{Aim of the Study}

This study aims to offer optimal bonus-malus premium scales for Turkey by examining experience rating and employing credibility theory. As from 2014, Turkish insurance companies have had complete freedom of using their own bonus-malus rates. Companies are obliged to use old class system and transition rules but may set up the premium scales they want. As there are not mandatory bonus-malus rates any more, a need for effective, optimal and financially fair system which is based on policyholder's own claim frequency has emerged. The aim of this study is to offer a new approach which can suggest a solution different from the traditional bonus-malus system.

\subsection{Methodology}

Fitting the data with Negative Binom distribution is investigated through $\chi^{2}$ test of goodness-of-fit. Parameter estimations obtained by means of moments method and bonus-malus system based on Negative Binom model, which has immensely taken its place in the relevant litareture, has been built employing credibility method

\subsubsection{Negative Binomial Distribution}

Negative Binomial distribution, which is a mixed Poisson distribution, is frequently preferred for modelling automobile's claim frequencies. At times, it is more appropariote to use a claim frequency distribution that shows overdispersion rather than using Poisson distribution whose mean equals its variance due to the pattern of portfolio's claim. Negative Binom distribution has more flexibility than Poisson distribution as it has two parameters (Klugman, Panjer, \& Willmot, 2012). Because of these reasons, Negative Binom distribution has often been preferred as an alternative of Poisson distribution in order to model overdispersed portfolios (Denuit, Maréchal, Pitrebois, \& Walhin, 2007). The portfolio is thought to be heterogeneous and all insureds have constant but unequal underlying risks to have an accident. Suppose that the number of claims $k$, given the parameter $\lambda$, is distributed according to Poisson $(\lambda)$ and $\lambda$ is representing the different underlying risk of each policyholder to have an accident. General form of mixed Poisson distribution as follows; (Dionne \& Vanasse, 1989).

$$
p_{k}=\int_{0}^{\infty} \frac{e^{-\lambda} \lambda^{k}}{k !} u(\lambda) d \lambda \quad k=0,1,2, \ldots
$$

For the structure function $u(\lambda)$ that $\lambda$ distributed gamma $(a, \tau)$ (Antonio \& Valdez, 2012)

$$
u(\lambda)=\frac{\tau^{a} e^{-\tau \lambda} \lambda^{a-1}}{\Gamma(a)} \quad a>0, \tau>0
$$

The distribution $\left\{p_{k} ; k=0,1,2, \ldots\right\}$ of the number of claims in the portfolio will be Negative Binomial $(a, \tau)$ with probability density function (Corlier et al., 1979). 


$$
p_{k}=\left(\begin{array}{c}
k+a-1 \\
k
\end{array}\right)\left(\frac{\tau}{1+\tau}\right)^{a}\left(\frac{1}{1+\tau}\right)^{k}
$$

Mean equal to $m=\frac{a}{\tau}$ and variance equal to $\sigma^{2}=\frac{a}{\tau}\left(1+\frac{1}{\tau}\right)$. The variance of the Negative Binomial exceeds its mean and allows us to deal with portfolio that present overdisperison. (Frangos \& Vrontos, 2001).

The easiest way to compute negative binomial probabilies is to use the recursion,

$$
p_{k+1}=\frac{k+a}{(k+1)(1+\tau)} p_{k}
$$

starting from

$$
p_{o}=\left(\frac{\tau}{1+\tau}\right)^{a}
$$

moment estimators of the parameters as fallows: (Lemaire, 1995)

$$
\hat{\tau}=\frac{\bar{x}}{s^{2}-\bar{x}}, \quad \hat{a}=\frac{\bar{x}^{2}}{s^{2}-\bar{x}}
$$

\subsubsection{Fitting the Negative Binomial Distribution to Data}

Fitting an observed distribution by a negative binomial entails, for the moment method (eq.6), identifiying $\mathrm{m}$ and $\sigma^{2}$ with the observed values $\bar{x}=0.0692$ and $s^{2}=0.0789$. This leads to the estimators $\hat{\tau}=\frac{\bar{x}}{s^{2}-\bar{x}}=7.1270$ and $\hat{a}=\frac{\bar{x}^{2}}{s^{2}-\bar{x}}=0.4932$.

Probabilities of Negative Binomial distribution has computed via equations (4\&5) and expected frequencies have been find out via multiplying probability values with observation number $n$. Observed and fitted distribution of number of claims of Negative Binomial distribution model is shown in Table 2.

Table 2. Observed and fitted distrubution of number of claims

\begin{tabular}{ccc}
\hline$k$ & $n_{k}$ & $n p_{k}$ \\
\hline 0 & 47837 & 47838.6 \\
1 & 2908 & 2903.2 \\
2 & 262 & 266.7 \\
3 & 28 & 27.3 \\
4 & 4 & 2.9 \\
$>4$ & 0 & 0.3 \\
Total & 51039 & 51093.0 \\
\hline
\end{tabular}

Table 2 shows that the fit is good. Observed and theoretical frequencies are too close. The fit is tested by $\chi^{2}$ test of goodness-of-fit.

Hypothesis;

$H_{o}=$ The data are governed by the negative binomial distribution

$H_{s}=$ The data are not governed by the negative binomial distribution

The expected frequency is supposed to be at least 5 in order to ensure that chi-square approximation is valid. The bins containing expected values less than 5 are combined. The result of $\chi^{2}$ test of goodness-of-fit: $\chi_{\text {calc }}^{2}=0.16<\chi_{1 ; 0,05}^{2}=3.84$. The chi-square test fails to reject the null hypothesis, so we can conclude that there is no significant difference between the observed and expected value.

\subsection{Building of Optimal Bonus-Malus System}

An Optimal bonus-malus system have been built by negative binomial model, which has fitted the data, by using 
credibility theory and experience rating. Calculations are limited to ten years $(t=10)$ and 6 claims $(k=6)$. As a premium principle, expected value premium principle that requires the policyholder to pay a net premium plus a security loading $(1+\alpha)$ propotional to that net premium is used in the model.

This principle refers to the notaion that the policyholder who faced claims history $\left(k_{1}, \ldots, k_{t}\right)$ will have to pay a Premium (Leamire, 1985).

$$
P_{t+1}\left(k_{1}, \ldots, k_{t}\right)=(1+\alpha) \lambda_{t+1}\left(k_{1}, \ldots, k_{t}\right)=(1+\alpha) \frac{a+k}{\tau+t}
$$

We apply the method above to the portfolio of 51.039 policyholders analyzed and represented by the parameters $\hat{a}=0.4932$ and $\hat{\tau}=7.1270$. Since we are not so much interested in the absolute values of $P_{t+1}\left(k_{1}, \ldots, k_{2}\right)$ as in the differences between the various classes, we will present the results so that the premium for a new policyholder is 100. The posterior premium, thus scaled, is equal to (Lemaire, 1979);

$$
P_{t+1}\left(k_{1}, \ldots, k_{t}\right)=\frac{100 \frac{a+k}{\tau+t}}{\frac{a}{\tau}}
$$

As each company is able to decide their own security loading $(1+\alpha)$, it does not seem necessary to include the calculations in this study. By using $\hat{a}=0.4932$ and $\hat{\tau}=7.1270$ we attain optimal BMS fit for the behavior of Turkish drivers. It is represented in the Table 3 indicating the premium that is supposed to be paid a insured causing $k$ accident in $t$ years, derived the primary premium is 100 .

Table 3. Bonus-Malus premiums of negative binomial model

\begin{tabular}{cccccccc}
\hline & \multicolumn{7}{c}{ Number of Claims $(k)$} \\
\cline { 2 - 7 } Years $(t)$ & 0 & 1 & 2 & 3 & 4 & 5 & 6 \\
\hline 0 & 100 & & & & & \\
1 & 87.70 & 265.50 & 443.31 & 621.12 & 798.93 & 976.73 & 1154.54 \\
2 & 78.09 & 236.41 & 394.74 & 553.07 & 711.39 & 869.72 & 1028.04 \\
3 & 70.38 & 213.07 & 355.76 & 498.45 & 641.14 & 783.84 & 926.53 \\
4 & 64.05 & 193.92 & 323.79 & 453.66 & 583.52 & 713.39 & 843.26 \\
5 & 58.77 & 177.93 & 297.09 & 416.25 & 535.41 & 654.57 & 773.72 \\
6 & 54.29 & 164.37 & 274.46 & 384.54 & 494.62 & 604.70 & 714.78 \\
7 & 50.45 & 152.74 & 255.03 & 357.32 & 459.61 & 561.90 & 664.19 \\
8 & 47.11 & 142.64 & 238.17 & 333.70 & 429.22 & 524.75 & 620.28 \\
9 & 44.19 & 133.80 & 223.40 & 313.00 & 402.61 & 492.21 & 581.82 \\
10 & 41.61 & 125.98 & 210.36 & 294.73 & 379.10 & 463.47 & 547.85 \\
\hline
\end{tabular}

Table 3 suggesst that, as stated previously, the premium of the policyholder who enters the system for the first is scaled as 100 . When a policyholder has a year without any claim he will get a $12.30 \%$ bonus so that the premium he has to pay is 87.70 . If he has another without making any claims his premium decreses to 78.09 . If the policyholder does not make any claim for ten years his premium will be reduced to 41.61 , so he will have got $58.39 \%$ bonus. On the contrary, if a policyholder who enters the system for the first time makes a claim during the first year he will be punished with $165.50 \%$ maluses and his premium will increase to 265.50 the following year. In the first year if he makes a claim twice, his premium will increase to 443.31. Similary, if he makes a claim three times in his first year, his premium will go up to 621.12. In this way, if he makes six claims in first year, he will be panalyzed with $1054.54 \%$ malus and his premium increases to 1154.54 . If a policyholder makes one or more claims during his diriving lifetime, he has to face very high maluses. A policyholder who has made a claim will have to wait at least for 15 years to get a bonus again. These high malus rates will encoruge the policyholders to drive more carefully.

\section{Conclusion}

In this study, we have constructed an optimal bonus-malus system with the aim of guiding insurance companies 
to set their bonus-malus rates effectively after free tariff regime has been forced in Turkey. The bonus-malus rates which have been identified are very different from the previous mandatory bonus-malus system's rates. Unlike the previous system, in this study, the policyholder has to bear high maluses over a long period of time if he makes any claims. Overall results imply that the new bonus-malus rates, which we have offered, has a lot of pros on the part of the insurer. Given the fact that the bonuses and maluses compensate for each other in the long term, it is financially balanced and fair in Bayesian sense. To go into detail, each policyholder has to pay a premium proportional to the estimate of his claim frequency by taking into consideration all the information attained in the past. In the previous mandatory bonus-malus system, policyholders could have gathered in the bonus zone, which caused the insurers to collect less premiums and put them at a disadvantage. On the other hand, in the new system, in the long term, every insured will a pay a premium that corresponds to own risk, which eliminates the disadvanteges of the previous system.

\section{References}

Antonio, K., \& Valdez, E. A. (2012). Statistical Concepts of A Priori And A Posteriori Risk Classification In Insurance. Statistical Concepts of a Priori and a Posteriori Risk Classification in Insurance, (96), 187-224. http://dx.doi.org/10.1007/s10182-011-0152-7

Bühlmann, H. (1967). Experience Rating and Credibility. ASTIN Bulletin, 4(3), 199-207. http://dx.doi.org/10.1017/S0515036100008989

Corlier, F., Lemaire, J., \& Muhokolo, D. (1979). Simulation of an Automobile Portfolio. The Geneva Papers on Risk and Insurance Theory, 4, 40-46.

Denuit, M., Maréchal, X., Pitrebois, S., \& Walhin, J. F. (2007). Actuarial Modelling of Claim Counts: Risk Classification, Credibility and Bonus-Malus Systems. John Wiley \& Sons.

Dionne, G., \& Ghali, O. (2005). The (1992) Bonus-Malus System In Tunasia: An Empirical Evaluation. The Journal of Risk and Insurance, 72(4), 609-663. http://dx.doi.org/10.1111/j.1539-6975.2005.00141

Dionne, G., \& Vanasse, C. (1989). A Generalization of Automobile Insurance Rating Models: The Negative Binomial Distribution With A Regression Component. ASTIN Bullettin, 19(2), 199-212.

Durak, T., \& Erdoğan, K. (2010). Trafik Sigortaları'nda Ödül-Ceza Sistemi Üzerine Bir Uygulama. Reasürör, 4-13.

Frangos, N. E., \& Vrontos, S. D. (2001). Design of optimal bonus-malus systems with a frequency and severity component on an individual basis in automobile insurance. ASTIN Bulletin, 31(1), 1-22. http://dx.doi.org/10.2143/AST.31.1.991

Frees, E. W. (2010). Regression Modelling with Actuarial and Financial Applications. New York: Cambridge University Press.

Kaas, R., Goovaerts, M., Dhaene, J., \& Denuit, M. (2008). Modern Actuarial Risk Theory Using R. Berlin: Springer.

Klugman, S. A., Panjer, H. H., \& Willmot, G. E. (2012). Loss Models: From Data to Decisions. New Jersey: John Wiley \& Sons.

Lemaire, J. (1979). How to Define a Bonus-Malus System With An Exponential Utility Function. ASTIN Bulletin, 10(3), 274-282. http://dx.doi.org/10.1017/S0515036100005900

Lemaire, J. (1985). Automobile Insurance: Actuarial Models. Boston: Kluwer Academic Publisher.

Lemaire, J. (1995). Bonus-Malus Sytems In Automobile Insurance. Boston: Kluwer Academic Publisher.

Lemaire, J. (1998). Bonus-Malus Systems:The European and Asian Approach to Merit-Rating. North American Actuarial Journal, 2(1), 26-38. http://dx.doi.org/10.1080/10920277.1998.10595668

Mert, M., \& Saykan, Y. (2005). On A Bonus-Malus System Where The Claim Frequency Distribution Is Geometric And The Claim Severity Distribution Is Pareto. Hacettepe Journal of Mathematics and Statistics, $34,75-81$.

Morillo, I., \& Bermúdez, L. (2003). Bonus-malus system using an exponential loss function with an Inverse Gaussian distribution. Insurance: Mathematics and Economics, 33, 49-57. http://dx.doi.org/10.1016/S0167-6687(03)00142-2

Tremblay, L. (1992). Using the Poisson Inverse Gaussian in Bonus-Malus Systems. ASTIN Bulletin, 22(1), 97-106. http://dx.doi.org/10.2143/AST.22.1.2005129 
Walhin, J. F., \& Paris, J. (1999). Using Mixed Poisson Processes in Connection with Bonus-Malus Systems. ASTIN Bulletin, 29(1), 81-99. http://dx.doi.org/10.2143/AST.29.1.504607

\section{Copyrights}

Copyright for this article is retained by the author(s), with first publication rights granted to the journal.

This is an open-access article distributed under the terms and conditions of the Creative Commons Attribution license (http://creativecommons.org/licenses/by/3.0/). 